\title{
Micro-strategies of Post-method Language Teaching Developed for Iranian EFL Context
}

\author{
Parviz Birjandi \\ Department of TEFL, Science and Research Branch, Islamic Azad University, Tehran, Iran \\ Mohammad Hashamdar \\ Department of Translation Studies, Karaj Branch, Islamic Azad University, Karaj, Iran
}

\begin{abstract}
This paper is intended to develop some micro-strategies for macro-strategies proposed by Kumaravadivelu's post-method framework. In his framework, he suggested ten macro-strategies, for each of which he suggested one or two micro-strategies. Some of those micro-strategies cannot be used or applied in Iranian context. The researchers decided to select 24 language teachers randomly to participate in the study. First, the macro-strategies proposed by Kumaravadivelu were taught along with the micro-strategies for each macro-strategy. However, the micro-strategies did not match the Iranian EFL context. Therefore, the researchers requested the participants to reflect and come up with some applicable micro-strategies for each macro-strategy. Then the micro-strategies suggested by the participants were trimmed and modified for better feasibility.
\end{abstract}

Index Terms - macro-strategy, language awareness, micro-strategy, learning opportunity, heuristics

\section{INTRODUCTION}

Language teaching has undergone many changes throughout its history in the world of sciences. Some of the changes have been considered beneficial and others in vain. However, at the beginning of the nineteen decade of this century, the changes came to an end due to proposal of post-method by some scholars of the field. Scholars such as Allwrigth (1991), Stern (1992), and Kumaravadivelu (2003) wrote on the death of methods and alternative to methods rather than alternative methods. This initiated a new era in language teaching which is called Post-method. The proposal of postmethod era started more than two decades ago. Nevertheless, based on the result of a survey conducted by the researcher, in many foreign language institutes post-method was rarely implemented in their language teaching. The survey indicated that a number of English teachers were not familiar with the concepts and some who knew something about them were not aware of how to apply the tenets of Post-method in language teaching.

This study attempts to familiarize EFL teachers with the principles and later to guide them to manipulate the principles in their teaching. In other words, the present study wishes to educate and train post-method language teachers.

Originally Kumaravadivelou's framework consisted of five macrostrategies which were all supported with classroom data. Later, he added five more macrostrategies to his framework. In order to come up with the idea of Post-method, he started reading about poststructuralism, postmodernism, and postcolonialism. His framework contains two sections: (a) macrostrategies, and (b) micro-strategies. Kumaravadivelou (2007) stated that "Macrostrategies are general plans derived from currently available theoretical, empirical, and pedagogical knowledge related to L2 learning and teaching" (p. 201). As it has been stated, a macrostrategy is a broad guideline based on which teachers can construct their location-specific, need-based microstrategies or classroom procedures. In other words, macro-strategies are operationalized in the classroom through microstrategies. It should be noted that macrostrategies are considered theoryneutral, because they are not confined to the assumptions of any one specific theory of language, learning, and teaching which exist in different methods. They are also considered method-neutral because they are not conditioned by a single set of principles or procedures associated with language teaching methods. Macrostrategies comprise ten types of strategies, each of which owns two to three macro-strategies adjusted for Iranian context.

\section{MAXIMIZE LEARNING OPPORTUNITIES}

This macro-strategy reiterates that teaching is a process of creating and utilizing learning opportunities. Teachers are seen both as creators of learning opportunities for their learners and users of learning opportunities created by learners. Teachers need to produce a balance between their role as planners of teaching acts and their role as mediators of learning acts. Kumaravadivelou (2003) believed "the best way we can maximize learning opportunities in our classes is through meaningful learner involvement" (p. 48). Learner involvement helps both the learners and the teachers to make informed choices. Norton (2000) proposed the notion of 'learner investment' as a facet of learner involvement and believed that "when language learners speak, they are not only exchanging information with target language speakers, but they are constantly organizing and reorganizing a sense of who they are and how they relate to the social world. 
Thus, an investment in the target language is also an investment in a learner's own identity, an identity which is constantly changing across time and space" (cited in Kumaravadivelou, 2003, p. 48). When learners pose a question or say something, even if it appears to be removed from the topic of discussion, they might possibly be creating learning opportunities.

Now the study is intended to propose some micro-strategies for five macro-strategies out of total ten of them.

\section{Suggested micro-strategy 1: Competition game}

Competition game is one of the most intriguing ways of maximizing learning opportunities. Learners prefer to be silent and inactive when they are solely asked to do different tasks. However, if they are requested to do game and finish a task or activity, they will be more interested in participating in the activity. There is a variety of competition games which can be played in English classes such as word knowledge game, function game, reading comprehension game, listening comprehension game, and many other games. For example, one session the teacher can ask the learners to establish two volunteer groups to contest a word knowledge game. The group should have a leader or head. Then, the teacher asks the first group to pose a vocabulary question which should be answered by the members of the second group. If the second group members could give the meaning of the word, then they are given one positive point and the first group should ask their second question. The questions are successively asked by the first group if the second group can answer the questions. If not, it goes to the second group turn to ask their question and now the first group members should answer the questions. The total number of questions should already have been assigned by the teacher at the beginning of the game so that the group which had more chances of answering, would be the winner of the game.

\section{Suggested micro-strategy 2: Cyberspace}

This micro-strategy is best applicable for all four skills and both vocabulary and grammar learning. Teachers can request the learners to follow the following steps to maximize their learning opportunities in reading skill and vocabulary:

First, ask the learners to surf the net and find an English magazine or a daily newspaper. Next, they are required to provide you with a number of new vocabularies with the guessed meanings. They should not look the new words up in dictionaries. The teacher can randomly check the text with the underlined new words and guessed meanings. By doing so, learners learn that as soon as they see a new word in a text, they are to guess the meanings.

Now for reading comprehension, the teacher asks learners to follow a top-down approach and decipher the whole idea of the text rather than word by word, or sentence by sentence of the text. Variety plays a crucial role here. The teachers should ask the learners to read a variety of texts ranging from political texts to sports and classified advertisements. Then, the learners are given time to talk about the text they read.

There is a fundamental problem permeating into majority of English classes in Iranian context. Most Iranian teachers (no idea about the foreign countries) ignore the techniques of reading comprehension while they are teaching reading skill. In reading section of their classes, they prefer to ask learners to read the text word by word and sentence by sentence loudly. When they are asked to utter their logic for doing so, they say they want to check learners' pronunciation and the meaning of new words. What they do for improving the reading skill of the learners is nothing. This can be the main reason of reading comprehension problem of Iranian learners. When nothing has been done for beefing up the reading comprehension skill, why should we expect them to have good reading comprehension skill?

In order to maximize learning opportunities for listening skill, cyberspace can be beneficial as well. Some news websites such as CNN, VOA, BBC, and other news agencies can be introduced to learners to visit and download pieces of news. Then, they are asked to write or tell the whole story without transcribing word by word of what they have heard.

\section{Suggested micro-strategy 3: Technology in use}

Technology has one major application and that is for the betterment of life. In the world of language teaching, technology can also be utilized for teaching the foreign or second language. The most frequent technological appliances are cell phones and MP3 or MP4 players. Teachers can take advantage of these technological instruments in the best way. For instance, the learners can be asked to use their cell phones for improving the listening skill. They can download different speeches of famous people and listen to them while walking or sitting aimlessly. The other use of technology might be the use of tablets for developing reading skill. They can download websites of their favorite magazines or newspapers and read them to find hot subjects to talk about them in their classes.

\section{FACILITATE NEGOTIATED INTERACTION}

This macro-strategy refers to meaningful learner-learner, learner-teacher interaction in class where the learners have the freedom and flexibility to initiate and manage talk, not just react and respond to it. However, the type of interaction is negotiated interaction which means that the learner should be actively involved in interaction as a textual, interpersonal, and ideational activity.

Halliday (1985) categorized interaction into three classifications: textual, interpersonal, and ideational. Interaction as a textual activity refers to the use of linguistic and metalinguistic features of language necessary for understanding language input. The linguistic dimension deals with phonological, syntactic, and semantic signals that enable learners and their interlocutors to understand input and transmit messages as intended. The metalinguistic dimension deals with the language awareness necessary to talk about language structures and mechanics. Interaction as an interpersonal 
activity refers to the use of language to promote communication between participants. Consequently, it involves sociolinguistic features of language required to establish roles, relationships, and responsibilities. It focuses on the nuances of interpersonal understanding, especially those necessary to open and maintain conversational channels and to identify and repair communication breakdowns.

And finally, interaction as an ideational activity refers to an expression of the participants' own experience of the processes, persons, objects, and events of the real or imaginary world in, around, and outside the situated learning and teaching context. Specifically, it focuses on ideas and emotions participants bring with them based on their life experiences, past and present. It also involves a cognitive awareness of, and a sociocultural sensitivity to the external world and its impact on the formation of individual identities.

Kumaravadivelu (2007) believed that micro-strategies for facilitating negotiated interaction should provide opportunities for learners to stretch their linguistic knowledge, improve their conversational capacities, and share their individual experiences.

The following micro-strategies which are applicable in Iranian context are proposed:

\section{Suggested micro-strategy 1: Striking a bargaining}

As the title sends signals, the main objective of this micro-strategy is to promote negotiated interaction through a cooperative decision-making activity that facilitates talk and topic management on the part of the learners. There are different ways to do so.

One way of enhancing negotiated interaction is through bargaining. Teachers can construct contexts in which compromising, agreeing, and negotiation are needed to achieve the goals. For example, teacher might ask learners to play roles as shop keepers and customers. One learner can act the part of a shop keeper who is hard to get bargain from and the other learner plays the role of a customer who is intended to haggle and buy the goods much cheaper. Throughout this negotiated interaction, a number of techniques should be used to maintain the negotiated interaction.

\section{Suggested micro-strategy 2: Hardtalk}

In this micro-strategy, teacher selects a hot potato to talk about in a free discussion panel for each week. It is highly recommended that teachers have a list of interesting topics for themselves and select one or two for each week. The class can be divided into two groups. The member of first group should support the topic and the members of the other group can disagree on the topic. The learners are to think and improvise the reasons for being pros and cons. Teachers can teach the learners the techniques and strategies for putting forth the best deduction and reasoning and the way they believe in some ideas despite their real feeling.

\section{Suggested micro-strategy 3: Critical thinking}

Being a critical thinker in education is not an easy job, especially, in Iranian context. Iranian learners grow up in such a way that they prefer to accept whatever they are told or written to. Teachers may ask the learners to choose a story book and read it completely. Then they are told to write their reflection on each chapter of the book. In the beginning it might sound difficult, but after some sessions the learners would learn how to do it in the best way.

\section{Minimize Perceptual Mismatches}

All agree that there is a gap between teacher and learner understanding and appreciation in the objectives and activities of classroom events. Although this distance might sometimes be unbridgeable, teachers should attempt to reduce it to minimum.

Block (1996) focused on the similarities and differences between learner and teacher perceptions of learning purpose and examined the ways in which learners describe and attribute purpose to the activities that teachers ask them to do. He found that while the teacher attached great importance to the job ad activity, which took too much class time, the learners "tended to write it off" (1994, p. 483). The learners spoke most highly of the news reviewing task, which, from the teacher's perspective, "hardly deserved mention." This study pointed "not only to the autonomy of learner thought but also to the existence of a gap between the way teachers and learners 'see' the classroom and all that occurs within it" (Block, 1996, p. 168).

In another study Barkhuizen (1998) focused on the students' perceptions of learning and teaching activities they encountered in their classes and found out that students' perception of classroom aims and events did not match those of their teachers. The teachers involved in the study were frequently surprised to learn about the thoughts and feelings of their students that, of course, were very different from theirs.

Kumaravadivelu (2003) identified ten sources that have the potential to contribute to the mismatch between teacher intention and learner interpretation: (1) cognitive mismatch which refers to the general, cognitive knowledge of the world that adult language learners bring with them to the classroom, (2) communicative mismatch which refers to the communicative skills necessary for the learners to exchange messages or express personal views, (3) linguistic mismatch which refers to the linguistic components such as syntactic, semantic, and pragmatic knowledge of the target language, (4) pedagogic mismatch which refers to the teacher and learner perceptions of stated or unstated short- or long-term instructional objectives of language learning tasks, (5) strategic mismatch that refers to operations, steps, plans, and routines used by the learner to facilitate the obtaining, storage, retrieval, and use of information, (6) cultural mismatch which refers to the knowledge of the cultural norms of the target language community expected to be minimally required for the learners to understand and solve a problem, (7) evaluative mismatch which refers to 
articulated or unarticulated types of self-evaluation measures used by learners to monitor their ongoing progress in their language learning activities, (8) procedural mismatch that refers to stated or unstated procedure or steps chosen by the learners to do a task, (9) instructional mismatch which refers to instructional guidance given by the teacher or indicated by the textbook writer to help learners carry out the task successfully, and (10) attitudinal mismatch that refers to participants' attitudes toward the nature of L2 learning and teaching, the nature of classroom culture, and teacherlearner role relationships.

\section{Suggested micro-strategy 1 : Hand in hand}

Cooperative learning is the type of learning which is highly appreciated in language learning. Teachers are requested to divide the class into some groups, in which there is one weak learner and one top student. This is done to teach learners that all should get improved and linguistic mismatches should be eliminated from among them. The type of question the teacher might ask should be indirect and groups are to answer the questions, not the individual learners. Even if a topic for research is given to learners, all members should seek the answer or solution.

\section{Suggested micro-strategy 2: Being on the same boat}

It has frequently been seen that some teachers try to lengthen the differences between themselves and learners. This manner sometimes turns out to be boastful for the purpose of indicating the superiority of the teacher over learners. That is not correct. If the objective of teaching is transferring knowledge and also morality and humanity to the learners, then extending the differences between teacher and learners cannot be appropriate. Teachers are requested to diminish cultural, cognitive, attitudinal, and procedural mismatches. They can choose topic for discussion but should not emphasize on their own beliefs and opinions. Learners' viewpoints can be right too. Even in language knowledge, teachers can pretend not to be the master of knowledge and sometimes they might show that they learn from their students. This would motivate learners to be more interested in the process of language learning. Teachers can show that the learners and they are all in the same boat for learning.

\section{Suggested micro-strategy 3: Think aloud}

In this micro-strategy, teachers give some minutes to learners to brainstorm the differences between themselves and the teacher or they might be asked to utter what they think of the differences and utter it with their own wordings. Then based on the utterances, the teacher can have the best sources of mismatches for those particular learners. Consequently, teachers try hard to minimize those mismatches to minimum status.

\section{Activate Intuitive Heuristics}

Heuristics refers to the process of self discovery on the part of the learner. It also refers to a method of teaching allowing the students to learn by discovering things by themselves and learning from their own experiences rather than by telling them things.

In the world of language learning and teaching, it means that an important task facing the language teacher is to create a rich linguistic environment in the classroom so that learners can activate their intuitive heuristics and discover the linguistic system by themselves. It is believed that language is systematic and rule-governed. For example, grammar which is a major component of language can be taught inductively. The inductive method of teaching is well suited to activate the intuitive heuristics of the learner. In inductive teaching, learners have an opportunity to encounter a grammatical structure or a language expression "several times in contexts where its relationship to the design of the language may be observed, and its meaning (structural, lexical, and socio-cultural) inductively absorbed from its use in such varying situations" (Rivers, 1964, p. 152).

Consciousness-raising and noticing the gap are two ways to attract the attention of the learners to language specifications, both of which have a direct impact on activating learners' intuitive heuristics. Consciousness-raising refers to a deliberate attempt to draw the learner's explicit attention to features of the target language, particularly to its grammatical features. Noticing gap refers to learners' ability to notice the gap between what they already know and what they need to know. Schmidt and Frota (1986, p. 311), who proposed what is called the "notice the gap principle," categorically state that "a second language learner will begin to acquire the target-like form if and only if it is present in comprehended input and 'noticed' in the normal sense of the word, that is consciously." For the purpose of noticing the gap, learners have to first recognize that there is something to be learned. Teachers can help learners in their cognitive act of connecting the known to unknown or new material by making linguistic features noticeable or recognizable.

\section{Suggested micro-strategy 1: Seeing is learning}

Learning vocabulary is sometimes considered the most difficult part of language learning. Accidental vocabulary learning can be regarded as a better way of vocabulary learning according to some scholars. For the purpose of improving intuitive heuristics, teachers are requested to ask learners to open their eyes and write down whatever word they do not know the meaning from class to home. Learners usually think that they must learn the new words within the class context. By this type of task, step-by-step, learners are acquainted to be new word conscious.

\section{Suggested micro-strategy 2: Research topic of the week}

It is not bad to pretend you have little or no knowledge about something. Teachers can sham they do not know something and can ask learners to search different books or people to find out the answer to those questions. For instance, teachers can give a topic to each learner to search and come up with enough information about it. Some minutes should be allotted to learners for the presentation of their findings. 


\section{Suggested micro-strategy 3: Surf the net}

The Internet is also a good and an easy source of obtaining information. Teachers can ask learners to search on the Internet to find some pieces of information about different issues such as the biography of some famous people, new places, new discoveries, state-of-the-art inventions, and other pieces of information. One thing which should be borne in mind is the follow-up procedure the teacher should be conscious about.

First, the teacher highlights names of people, places, and occasions which are considered as proper nouns, and then asks the learners to surf the net and find out what they mean. In this way, the learners would be familiar with some websites such as Wikipedia, Google, Yahoo, Mama's, and other search engines. They will learn where and how they should seek for their needed information. Moreover, they would quench their thirst of knowledge by searching on the Internet.

\section{Foster LANGUAGe Awareness}

There are different strands of thought about how language awareness can be fostered. They can be classified into two major types of awareness: (a) general language awareness, and (b) critical language awareness. The former refers to an awareness of linguistic and sociolinguistic features governing language usage, while the latter treats it primarily as an awareness of social and political factors governing language use. Language awareness was defined as "a person's sensitivity to and conscious awareness of the nature of language and its role in human life" (Donmall 1985, p. 7, cited in van Lier, 1996).

Language awareness is largely focused on the properties of language structure and language usage with particular reference to literacy skills (reading and writing). In addition, the efforts were mostly directed at language classes since these classes easily lend themselves to metalinguistic activities through which participants can objectify a language and talk about it. The efforts showed that there are interesting ways in which learners' attention can be explicitly drawn to the logic of a linguistic subsystem be it spelling, intonation, or grammar.

\section{Suggested micro-strategy 1: Speech act practices}

How various kinds of speech acts are said in target language in comparison with the native language of the learners can best represent language awareness. For instance, learners can be asked to say how a polite request is uttered in Persian and then watch some English movies and find out how it is said in English. In this way an array of language functions such as inviting, ordering, excusing, persuading, apologizing, and other functions can be worked out in the classroom.

\section{Suggested micro-strategy 2: Spell it out}

You have undoubtedly experienced a number of odd spellings and pronunciations in English language. Teachers are requested to draw the attention of the learners to these strange and idiosyncratic spellings and pronunciations. For instance, language awareness of the learners can be raised to spelling of words such as cannot, maybe, of course, grammar, and conquer, the pronunciations of words such as chic, chandelier, pressure, driven, obligatory, and iron, the change of the meanings of words when part of speech is altered in words such as exhaustion (tiredness) and exhaustive (vast), refuse (reject) and refuse (rubbish), content (amount) and contented (satisfied). By virtue of this consciousness raising, the learners would be alerted that some parts of any language are not rule-governed and special attention.

\section{CONCLUSION}

Language teaching has entered a new era and consequently the new era and its principles should be introduced to language teachers. The researchers felt committed to do the task of introduction in Iranian context of language teaching. To do so, the researchers attempted to hold post-method courses in different language teaching centers in various cities in Iran. The courses were flooded by many English teachers, but due to lack of space, some highly motivated teachers were selected and categorized in different classes. While teaching Kumaravadivelu's Post-method framework, the participants (English teachers) were requested to propose some micro-strategies for each macro-strategy. The microstrategies should have met the criteria needed for Post-method language teaching in Iranian context. In this study, the researchers decided to propose the micro-strategies the students suggested with some modifications their suggestions needed. Therefore, English teachers can easily use these micro-strategies in English classes all over Iran.

\section{REFERENCES}

[1] Allwright, R. L. (1993). Integrating research and pedagogy: Appropriate criteria and practical problems, in J. Edge and K. Richards (eds.). Teachers develop teachers research. London: Heinemann.

[2] Allwright, R. L., and K. M. Bailey. (1991). Focus on the language classroom. Cambridge: Cambridge University Press.

[3] Barkhuizen, G. P. (1998). Discovering learners' perceptions of ESL classroom teaching/learning activities in a South African context. TESOL Quarterly, 32(1), 85-108.

[4] Block, D. (1994). A day in the life of class: Teachers/learner perceptions of task purpose in conflict. System 22(4), 473-86.

[5] Block, D. (1996). A window on the classroom: classroom events viewed from different angles, in K. M. Bailey and D. Nunan (eds.). Voices from the classroom: Qualitative research in language classrooms. Cambridge: Cambridge University Press.

[6] Kumaravadivelu, B. (1994). The postmethod condition: (E)merging strategies for second/foreign language teaching. TESOL Quarterly, 26(1), 27-50. 
[7] Kumaravadivelu, B. (2003). Beyond methods: Macrostrategies for language teaching. New Haven: Yale University Press.

[8] Kumaravadivelu, B. (2006). Understanding language teaching: From method to postmethod. Mahwah, NJ.: Lawrence Erlbaum.

[9] Norton, B. (2000). Identity and language learning. London: Longman.

[10] Prabhu, N. S. (1987). Second language pedagogy. Oxford: CUP.

[11] Richards, J. C. (1998). Beyond training: Perspectives on language teacher education. Cambridge: CUP.

[12] Rivers, W. M. (1964). The psychologist and the foreign language teacher. Chicago: University of Chicago Press.

[13] Stern, H. H. (1992). Issues and options in language teaching. Oxford: Oxford University Press.

[14] Van Lier, L. (1996). Introducing language awareness. London: Penguin.

Parviz Birjandi, professor holding a Ph.D. in English education; minor: Research methods and statistics from the University of Colorado. He is currently the Head of TEFL Department at Foreign Languages and Persian Literature in the Islamic Azad University, Science and Research Branch. He has taught different courses at Ph.D. and MA levels and published a number of articles in the area of TEFL and is the author of English textbooks for high school and pre-university levels, and many university textbooks taught all over Iran.

Mohammad Hashamdar received his MA in TEFL in 2001 and became a faculty member of Islamic Azad University, Karaj Branch. He is currently doing his PhD dissertation in TEFL at Islamic Azad University, Science and Research Branch. He has been teaching English at different levels for 23 years and has published eight books and some papers in international journals. His research interests are critical thinking, first language acquisition, second language acquisition, and methodology. 